\title{
A política de saúde mental no Estado do Espírito Santo
}

\author{
Edinéia Figueira dos Anjos Oliveira \\ Universidade Federal do Espírito Santo (UFES)
}

\author{
Maria Lúcia Teixeira Garcia \\ Universidade Federal do Espírito Santo (UFES)
}

\section{A política de saúde mental no Estado do Espírito Santo}

Resumo: O objetivo deste artigo é analisar a política de saúde mental e sua inserção no planejamento e na gestão dos municípios do estado do Espírito Santo ${ }^{1}$. Trata-se de uma pesquisa documental feita em relatórios de gestão municipal - dos Planos Municipais de Saúde, de 2006 a 2009, e dos Relatórios de Gestão de 2005 a 2007. Foram pesquisados 59 dos 78 municípios do estado para identificar as ações desenvolvidas, bem como os recursos distribuídos para o seu desenvolvimento. Os resultados da análise dos dados indicam que a saúde mental apareceu como item da agenda municipal em seu planejamento, mas sua configuração não garante que as ações propostas sejam efetivadas, pois não asseguram os recursos necessários à sua execução.

Palavras-chave: Política de saúde. Política de saúde mental. Descentralização. Espírito Santo.

\section{Mental Health Policy in Espírito Santo State}

Abstract: The purpose of this article is to analyze mental health policy and its insertion in the planning and administration of municipalities in Espírito Santo State. It involves document research, particularly that of Municipal Health Plans from 2006-2009 and municipal Management Reports from 2005-2007. Fifty-nine of the 78 municipalities of the state were studied to identify the actions undertaken, as well as the funds provided for their enactment. The results of the data analysis indicate that mental health appears as an item on municipal agendas in the planning stages, but there is no guarantee that the actions proposed are undertaken, because the resources needed for their execution are often not provided.

Key words: Healthcare policy. Mental health policy. Decentralization. Espírito Santo. 


\section{Introdução}

Segundo estimativas do Ministério da Saúde (BRASIL 2009), 3\% da população, cerca de 5 milhões de pessoas com transtornos mentais severos e persistentes, necessitam de cuidados contínuos em saúde mental e mais $9 \%$, aproximadamente 15 milhões de pessoas com transtornos menos graves, precisam de atendimento eventual. No processo de implementação da Política de Saúde Mental no país, a partir da promulgação da Lei n. 10.216 (BRASIL, 2001), o que se observa é o aumento progressivo de uma cobertura assistencial em saúde mental extrahospitalar, de base comunitária, mas aquém do necessário. Assim, o direito do sujeito com transtorno mental - de ser tratado em serviço comunitário de saúde mental, com vistas à inserção na família, no trabalho e na comunidade -, como estabelecido pela lei, não é assegurado em sua integralidade. Isto porque a cobertura dos serviços existentes assevera tratamento a 57\% da demanda da área (BRASIL, 2009).

Os dados, do Ministério da Saúde de 2009 apresentam uma rede em saúde mental composta por 1.394 Centros de Atenção Psicossocial (CAPS), 533 Serviços Residenciais Terapêuticos, 3.346 beneficiários do Programa de Volta para Casa e 35.426 leitos psiquiátrico no Sistema Único de Saúde (SUS), distribuídos desigualmente no território nacional. De acordo com o relatório, "apesar dos avanços, a rede precisa ser ampliada ainda mais" (BRASIL, 2009, online). Além disso, entre os desafios para o período 2007-2010, é apontada a necessidade de garantia da sustentabilidade da nova rede de atenção na construção do Pacto pela Saúde Mental e, consequentemente, da reforma psiquiátrica brasileira.

Assim, tendo em vista a necessidade de efetivação da reforma psiquiátrica brasileira, este trabalho se propõe a analisar se a política de saúde mental entrou no planejamento dos municípios do estado do Espírito Santo como item de gestão na área e que tipo de rede vem sendo construída. Parte-se do entendimento de rede de atenção em saúde mental como diametralmente oposta aos sistemas clássicos piramidais, hierarquizados, que incentivam o "hospitalocentrismo" e a burocratização. Rede aqui expressará sistemas decisórios horizontais, estruturados através de programação pactuada. Ou seja,

[...] é a organização horizontal de serviços de saúde, com o centro de comunicação na atenção primária à saúde ${ }^{2}$, que permite prestar uma assistência contínua à população - no tempo certo (acesso e acessibilidade), no lugar certo (território), com o custo certo (e não com menor custo) e com a qualidade certa (a maior) - e que se corresponsabiliza pelos resultados sanitários e econômicos relativos à população (BRASIL, 2006, online).

\section{Aspectos metodológicos}

Este trabalho faz uma pesquisa documental (MAY, 2004) sobre a implementação da política de saúde mental nos 78 municípios do estado do Espírito Santo.

Foram relacionados documentos que permitissem identificar o movimento dos municípios em direção à implementação da política de saúde mental, tais como o relatório de gestão e o plano municipal de saúde. Como instrumentos de gestão, esses documentos relatariam se (e em que momento) a política de saúde mental entrou na agenda como prioridade na gestão, quais ações foram desenvolvidas na área e quais ações da atenção básica foram priorizadas pelo município. Feita a relação dos 78 municípios, foram contatados secretários municipais de saúde, técnicos diretamente ligados aos gabinetes e coordenadores de saúde mental, solicitando cópias desses documentos. Os contatos foram feitos ou por correio eletrônico, telefone ou pessoalmente, por ocasião das reuniões da Comissão Intergestora Bipartite (CIB) e das microrregiões. A entrega dos documentos ocorreu a partir do último trimestre de 2007 e durante o ano 2008. Para aqueles que não enviaram, a solicitação foi feita pessoalmente nas Secretarias Municipais de Saúde. Foram obtidos documentos de 59 dos 78 municípios que compõem o estado do Espírito Santo.

Buscou-se identificar no plano de cada município as ações previstas para serem desenvolvidas no período de 2006 a 2009, as metas a serem alcançadas e os recursos previstos para a realização das ações. No relatório de gestão, objetivou-se identificar as ações priorizadas em saúde mental na atenção básica. As variáveis analisadas foram: ações desenvolvidas e recursos garantidos para o desenvolvimento das ações. Com isso, a análise buscava identificar se o processo de descentralização administrativa, implementado na política de saúde brasileira pós Constituição de 1988, possibilitou a existência de um projeto de saúde municipal que incorporasse na sua agenda as demandas da área da saúde mental.

\section{A reforma psiquiátrica brasileira: o processo de implementação e os marcos legais}

A Lei da Saúde Mental n. 10.216 (BRASIL, 2001) dispõe sobre um novo modelo assistencial de proteção e direito às pessoas portadoras de transtorno mental. Nessa linha, o Ministério da Saúde cria linhas específicas de financiamento para serviços substitutivos aos manicômios, como também gera mecanismos de fiscalização, gestão e redução programada de leitos psiquiátricos em todo o país. As ações do Governo Federal definem duas linhas de atuação: "a construção de uma rede de atenção à saúde mental" para substituir o modelo hospitalar e a 
"físcalização e redução progressiva e programada de leitos psiquiátricos" (TENÓRIO, 2002)

A rejeição ao modelo psiquiátrico segregário e excludente e a busca por um modelo de atenção com base comunitária, resultaram na adoção dos Núcleos de Atenção Psicossocial e dos Centros de Atenção Psicossocial (Napscaps) como serviços substitutos (JORGE et al., 2005). A atenção psicossocial, entendida como um novo paradigma para as práticas em saúde mental, apresenta-se, segundo o discurso da Política de Saúde Mental vigente, capaz de substituir o modelo psiquiátrico dominante. O termo psicossocial ganha estatuto de conceito a partir da década de 1980, quando se firmam os movimentos de crítica mais radical à psiquiatria - momento em que seu objeto é visto sob uma nova concepção. Novas relações terapêuticas são estruturadas e novos dispositivos institucionais passam a ser utilizados sob uma nova fundamentação teóricotécnica, contrapondo-se ao paradigma psiquiátrico no país. Esses novos dispositivos deveriam substituir a lógica manicomial hegemônica (COSTA-ROSA; LUZIO; YASUI, 2001).

A criação de CAPS para lidar com as demandas em saúde mental passa a ser o modelo preferencial da política de saúde mental brasileira. O "modelo psicossocial" considera diversos fatores (políticos, biológicos, psicológicos, sociais) como centrais para a configuração das práticas em saúde mental que devem ser conjugadas em suas atividades, visando à reintegração social (COSTA-ROSA; LUZIO; YASUI, 2001). Esse processo requer um reposicionamento do usuário que passa de simples sujeito portador de sofrimento psíquico para agente da possibilidade de mudanças.

A portaria n. 336/2002 (BRASIL, 2002) estabeleceu três modalidades de serviços para os CAPS $^{3}$ com garantia de financiamento. O Ministério da Saúde discrimina que a atenção psicossocial está prevista em lei para municípios com população acima de 20 mil habitantes, significando que aqueles de pequeno porte não têm garantia de financiamento para implantação deste em sua base territorial. Assim, aos municípios de pequeno porte, caberia estruturar ações através das equipes da Estratégia de Saúde da Família $(\mathrm{ESF})$ e na rede básica de atenção à saúde.

A proposta atual da política de saúde mental é a garantia da estruturação de uma rede de atenção integral constituída por vários dispositivos que possibilitem a atenção psicossocial às pessoas com transtorno mental. A rede deve contar com CAPS, Serviços Residenciais Terapêuticos (SRT), leitos em hospitais gerais, ambulatórios, bem como o Programa de Volta para Casa, além das ações de saúde mental na atenção básica (atendimento individual e/ou em grupos aos usuários e familiares, oficinas terapêuticas, estratégias de prevenção ao transtorno mental, entre outras), que podem ser desenvolvidas através das equipes mínimas de saúde mental articuladas à Es- tratégia Saúde de Família. Pensa-se em outros dispositivos que se caracterizam como atividades de cuidado e suporte social, sustentadas por ações intersetoriais, tais como trabalho protegido, lazer, advocacia de direitos e de questões previdenciárias (JORGE et al., 2005). A rede deve funcionar de forma articulada, tendo os CAPS como serviços estratégicos, desenvolvendo o papel de organizador e regulador dos serviços de saúde mental.

Alguns municípios e estados intensificaram o processo de mudança do modelo assistencial com a criação de CAPS ou equipe mínima de saúde mental. Entretanto, na maioria das regiões do país, o processo tem se dado de forma lenta. Na Região Norte do Brasil, a cobertura de um CAPS por 100 mil habitantes em 2002 era em média de 0,11 e em 2006 subiu para 0,27. Na Região Nordeste, de 0,12 em 2002, subiu para 0,55 em 2006. Na Região Centro-Oeste, de 0,15 , em 2002, subiu para 0,36, em 2006. Na Região Sudeste, de 0,24, em 2002, subiu para 0,40, em 2006. Na Região Sul, de 0,31, em 2002, subiu para 0,44 , em $2006^{4}$. Entretanto, há que se observar dentro de uma mesma região que alguns estados ultrapassam o indicador de cobertura de CAPS, enquanto outros apresentam vazios de serviços.

Identifica-se a permanência da centralidade do hospital psiquiátrico no Sistema de Saúde. Em 2002, em todo o país, havia 51.393 mil leitos psiquiátricos e em 2006 o número caiu para 39.567. Essa redução de 11.826 (23\%) do total de leitos existentes - ocorreu muito mais em hospitais públicos que nos privados (BRASIL, 2007). Pelo parâmetro do Ministério da Saúde, que prevê a necessidade de 50 leitos para cada 100 mil habitantes, o objetivo da política de desospitalização do doente psiquiátrico teria sido alcançado nas diversas regiões, com exceção da Região Sudeste (ANDREOLI, 2007). Este mesmo autor afirma que ocorreu uma diminuição importante de leitos psiquiátricos e, em contrapartida, um aumento de serviços comunitários - o que, por um lado, indicaria avanço no processo de implantação da política de saúde mental. No entanto, não foram repassados para os serviços comunitários os recursos gastos anteriormente com internações psiquiátricas. Andreoli (2007) chama a atenção para o fato de que, embora tenham diminuído as despesas com leitos psiquiátricos, o índice de gastos com hospitalização de doentes mentais ainda permanece grande. A hospitalização consumiu 93,2\% do dinheiro gasto pelo governo brasileiro com a saúde mental em 1997. O ano de 2006 foi o primeiro em que os gastos extra-hospitalares superaram os gastos do programa com os hospitais psiquiátricos.

Entretanto, outros indicadores merecem ser analisados, por exemplo, a distribuição espacial dos serviços no território nacional, a acessibilidade destes aos usuários e o tipo de assistência prestada. Outro as- 
pecto diz respeito ao tipo de assistência prestada, que, em alguns casos, reproduz uma perspectiva clínica médico-centrada e não uma perspectiva psicossocial.

É importante lembrar que o processo de desinstitucionalização, como parte da reforma psiquiátrica, não depende só de medidas normativas; pressupõe transformações socioculturais, uma vez que deve garantir a reintegração na comunidade das pessoas com transtornos mentais graves e persistentes (AMARANTE, 2007). Depois do longo período de exclusão, controle e violência contra aqueles que sofrem de transtorno mental, apresentam-se tarefas mais difíceis: reabilitar o "louco" a fim de propiciar seu convívio junto à comunidade como também reeducar essa mesma comunidade para que todos possam conviver e desfrutar de uma mesma coletividade. As mudanças a serem aprovadas e formuladas implicaram, e ainda implicam, no enfrentamento de resistências. Isto porque havia, e ainda há, grupos a favor da manutenção do antigo modelo, como a indústria farmacêutica, os empresários do ramo hospitalar e alguns psiquiatras. Esta é uma arena onde não há consenso, atravessada por múltiplos e diferentes interesses.

É preciso cautela e cuidado ao analisar os dados do Ministério da Saúde. Há que ser, ao mesmo tempo, pessimista e otimista. Pessimista, pois ainda há muitos sujeitos sem garantia de acesso a serviços de saúde mental. A rede de saúde mental ainda não foi constituída dentro dos princípios do SUS. Por exemplo, a expansão dos CAPS específicos ${ }^{6}$ - CAPS álcool e drogas (CAPSad), CAPS infantil (CAPSi) e CAPS III - tem sido o principal desafio. Por serem inovações e envolverem tecnologias complexas, essas três modalidades preveem assegurar a qualidade do atendimento, com a característica de serviços abertos, territoriais, de atenção diária. Notadamente, o CAPS III foi o tipo de serviço com menor expansão durante o período, por se tratar de um dos dispositivos de maior complexidade da rede e por enfrentar o preconceito cultural quanto à necessidade estrita da internação hospitalar.

Mas há também que ser otimista. Há uma tendência de enfrentamento, por parte da área técnica da saúde mental, no sentido de fazer avançar a reforma psiquiátrica. Por exemplo, a decisão política pela composição de uma rede pública de CAPS do Ministério da Saúde enfrenta resistências quanto à contratação de serviços privados, em caráter complementar. Prova disso é que, a partir de 2003, apenas CAPS públicos (em sua quase totalidade, municipais) foram cadastrados junto ao Ministério da Saúde. Houve incentivo à municipalização dos poucos serviços privados ou filantrópicos, existentes há mais tempo na rede, e que prestassem atendimento relevante. Assim, em 2007, 98,6\% dos CAPS da rede são públicos.
A composição da rede de saúde mental proposta pelo Ministério da Saúde recomenda sua estruturação considerando o tamanho dos municípios. Quanto maior o tamanho do município, maior a complexidade de recursos a serem disponibilizados em todos os níveis de atenção. Como um processo lento, os CAPS existentes estão longe de atingir as metas da política. Há um déficit na oferta de todos os tipos de CAPS, indicando um longo percurso a ser trilhado na construção de uma rede horizontalizada que permita prestar uma assistência contínua à população.

Nessa análise, soma-se ao otimismo um pessimismo da razão. Pessimismo quanto às ações da Federação Brasileira dos Hospitais particulares $(\mathrm{FBH})$ que tentam obstaculizar ou inviabilizar as mudanças pretendidas. A FBH preocupa-se com a manutenção e o crescimento da iniciativa privada, defendendo a questão da lucratividade no âmbito das ações da saúde, argumentando que a garantia da saúde financeira da empresa é o que garante o atendimento aos seus associados (FBH, 2007).

Otimismo, em face às novas práticas que vêm sendo experimentadas nos serviços de saúde mental em diferentes regiões do país, que contribuem para desconstruir a imagem estereotipada do "louco".

Contudo, o pessimismo justifica-se, pois o processo de desinstitucionalização, expressão de luta e avanço de direitos, inscreve-se na contramão do projeto científico, político e econômico dominante: o neoliberalismo. Um claro exemplo é o financiamento da saúde mental. Enquanto a arrecadação de tributos destina $60 \%$ para a União, $24 \%$ para os estados e $16 \%$ para os municípios, a responsabilidade do financiamento da saúde em 2007 foi de $47 \%$ para a União; $26 \%$ para os estados e $27 \%$ para os municípios. Essa sistemática de financiamento da saúde vem onerando sobremaneira os municípios e desonerando a União.

A descentralização político-administrativo implementada no Brasil pós-1988 confunde-se com a municipalização das ações governamentais, por assumir claramente o sentido de transferência de poder, recursos e responsabilidades do nível federal para o nível municipal, sobretudo no que se refere à provisão de serviços sociais. O modelo de atenção à saúde no Brasil define a plena responsabilidade do poder público municipal que deve assumir, ainda que não isoladamente, as ações de saúde. O município passa a ser o responsável direto pelo atendimento das necessidades e demandas de saúde da sua população tendo como co-responsáveis os poderes públicos estadual e federal.

Entretanto, a realidade dos municípios é muito diferenciada - em sua maioria municípios de pequeno porte com baixa capacidade financeira e administrativa -, caracterizando diferentes possibilidades de desenvolver ações, ao se considerar a disponibilida- 
de de recursos, a capacitação gerencial e o perfil epidemiológico (SOUZA, 2005).

Enfim, há muito que avançar e há muitos riscos e limites nesse caminho de implementação da política de saúde mental. É à luz dessas reflexões que se focalizou a questão em um estado brasileiro em particular: o estado do Espírito Santo.

\section{O processo de reforma psiquiátrica no Espírito Santo}

O estado do Espírito Santo, localizado na Região Sudeste do Brasil, é constituído por 78 municípios, em sua maioria de pequeno porte ${ }^{7}$ e possui uma população total de 3.351.669 habitantes (ESPÍRITO SANTO, 2010). Entre os estados que compõem as regiões Sudeste e Sul do Brasil, o Espírito Santo é o menos populoso (BRASIL, 2007a).

Historicamente, o modelo de atenção em saúde mental no Espírito Santo centrou-se na hospitalização em grandes hospitais psiquiátricos públicos e privados. O processo de reestruturação da assistência psiquiátrica iniciou-se em 1985, quando foi realizado, em Vitória, o I Encontro Nacional dos Coordenadores de Saúde Mental da Região Sudeste (um dos precursores da realização da I Conferência Nacional de Saúde Mental). O debate intensificou-se no estado com a realização do II Encontro de Coordenadores de Saúde Mental, realizado em 1992, abrindo espaço para o amadurecimento de propostas a serem apresentadas na II Conferência Nacional de Saúde Mental. A partir de 1995, o estado do Espírito Santo se coloca de forma efetiva no contexto da reestruturação da assistência psiquiátrica no país, destacando dois fatores decisivos para isso: a) a definição clara para os estados e municípios de uma política nacional de saúde mental, prescrita no contexto da década de 1990; b) a eleição, em 1994, de um governo estadual popular e democrático que priorizou a política de saúde. Esses dois fatores constituíram um terreno favorável à discussão de uma política nacional de saúde mental para o Espírito Santo. Em 1995, o número de hospitais psiquiátricos no estado somava quatro instituições. Ferreira (2005, p. 125) descreve o cenário de 1995 da seguinte maneira:

O Hospital Adauto Botelho (HAB), maior hospital público do Estado, abrigava uma clientela constituída por cerca de $80 \%$ de pacientes moradores e/ ou de longa permanência. Não havia local destinado a tratamento específico para os diferentes perfis de clientela ali encontrados. Os atendimentos a pacientes em quadro agudo eram realizados em qualquer enfermaria onde houvesse vagas para internação [...] inexistia o planejamento do tratamento durante o período de internação nem tampouco havia preparação para alta hospitalar [...] A falta de preparo dos profissionais de saúde para realizar uma primeira abordagem nessas situações e a não disponibilidade de leitos em hospital geral para urgência psiquiátrica levava-os a recorrerem às delegacias de polícia locais ou às Secretarias de Ação Social para solucionar os casos que, quase sempre, resultavam na internação do paciente em hospital psiquiátrico.

Os dados de internação psiquiátrica entre 1995 e 2002 apresentaram uma discreta tendência de redução global. Foi entre 1995 e 1999, momento de inúmeras ações do Estado na área de saúde mental, que os índices de internação apresentaram tendência de alta (maior alta em 1999). Como resposta, a Coordenação Estadual de Saúde Mental desenvolveu um conjunto de ações visando à redução nos índices de internação. Em 2003, 42\% dos municípios dispunham de algum serviço em saúde mental. O período de implantação desses serviços coincide com movimentos, inspirados na da II Conferência Estadual em Saúde Mental, que repassaram aos municípios a responsabilidade da atenção à saúde mental com criação de atendimentos ambulatoriais. Em 2005, a ampliação da rede ambulatorial atingiu 43 municípios $(55,1 \%)$. Na macrorregião sul, onde está localizada a Clínica Santa Isabel (CSI), houve o maior número de serviços implantados. Esse investimento, voltado para as ações de enfrentamento da manutenção da lógica manicomial, representada pela CSI, revela a titude de gestores e profissionais comprometidos com os princípios da reforma psiquiátrica.

No Espírito Santo, seguindo a diretriz nacional, a política de saúde mental hoje traz como proposta a redução progressiva dos leitos psiquiátricos, a qualificação dos profissionais que atuam na saúde mental, a expansão e o fortalecimento da rede extra-hospitalar, como CAPS, SRTs, unidades psiquiátricas em hospitais gerais, implantação do Programa de Volta para Casa e implementação das ações de saúde mental na atenção básica através das Equipes Mínima de Saúde Mental (ESPÍRITO SANTO, 2001). A rede de atenção é pensada: a) em nível ambulatorial, através da unidade básica de saúde, CAPS e ambulatório especializado em saúde mental; b) em nível hospitalar, através de hospital-dia, serviço de urgência psiquiátrica, leito ou unidade psiquiátrica em hospital geral e hospital especializado em psiquiatria; c) em serviços residenciais terapêuticos, através de casa lar, pensão protegida, centros de convivência (ESPÍRITO SANTO, 2001).

As internações psiquiátricas no ano de 2008, no estado, apresentaram uma concentração no município de Cachoeiro do Itapemirim. Neste município, localizam-se dois hospitais psiquiátricos: um público - o Centro de Atendimento Psiquiátrico Aristides Ale- 
xandre Campos -, com 35 leitos; e um privado e conveniado ao SUS - a CSI -, com 400 leitos. Das 3.274 internações registradas em Cachoeiro de Itapemirim, a maioria foi na CSI. Em 2008, foram 6.751 Autorizações de Internação Hospitalar (AIHs) para a CSI (uma média de 562 AIHs/mês) contra 656 AIHs para o outro hospital (DATASUS, 2009). A média/ano de dias de internação na CSI, em 2008, foi de 61,8 (ou seja, ultrapassa o recomendado pela PSM). Em 2007, 61,7\% do valor gasto pela Secretaria de Estado da Saúde em saúde mental foi para pagamento das AIHs da CSI.

A partir da análise feita, buscou-se levantar dados para o propósito desta pesquisa: identificar se a política de saúde mental entrou nos planejamentos municipais e avaliar em que condições ocorreu a gestão descentralizada da política nos municípios do estado do Espírito Santo.

\section{Resultados}

Dos 78 municípios do Estado, 48 (61,5\%) possuem serviço ambulatorial em saúde mental. Desses 48 municípios, 22 são considerados de pequeno porte e oferecem serviços na atenção básica através de equipes mínimas de saúde mental.

A denominada "rede" de atenção em saúde mental, em 2008, configura-se com a existência de 19 CAPS, 36 equipes mínimas de saúde mental em 36 municípios, 2 ambulatórios de referência, 5 serviços com consulta psiquiátrica situados no centro de referência de especialidades e policlínicas, 3 hospitais psiquiátricos com total de 485 leitos (dentre eles, um privado), 3 hospitais gerais totalizando 30 leitos psiquiátricos e 5 residências terapêuticas, que abrigam 40 ex-moradores do hospital psiquiátrico Adauto Botelho.

Considerando esses dados, verifica-se que a estratégia utilizada pela maior parte dos municípios para responder minimamente à política estadual de saúde mental tem sido a constituição da equipe mínima multiprofissional, composta por um médico e dois profissionais de nível superior, geralmente psicólogo e enfermeiro e/ou assistente social. Entretanto, estes municípios não têm garantia de uma rede de serviço de referência para pacientes egressos de hospitais psiquiátricos e de outros serviços de urgência.

Dos 36 municípios que implantaram as equipes mínimas, apenas 22 são de pequeno porte. Assim, há municípios de médio e grande porte que poderiam implantar outros dispositivos assistenciais (como CAPS) e ainda não o fizeram. Há apenas um CAPSi (localizado no município de Vitória) e não há nenhum CAPS III. Há concentração de leitos psiquiátricos na CSI, e é incipiente o número de leitos psiquiátricos em hospitais gerais.

Como o foco desta pesquisa é identificar se houve a inclusão da saúde mental, a análise feita nos 59 municípios, participantes do trabalho, observou que: 6 preveem no Plano Municipal de Saúde recursos para manutenção do serviço e 19 definiram ações e metas a serem perseguidas na área, seja através da atuação de uma equipe mínima de saúde mental, seja através de CAPS.

Desses 19 municípios, 6 possuem CAPS e os 13 restantes, equipes mínimas de saúde mental. Todos esses indicam metas a fim de: assegurar a atuação das equipes; adequar instalações físicas para o atendimento; implantar CAPS (em 3 municípios que ainda não as possuem); reduzir internações psiquiátricas; capacitar os profissionais da saúde para o atendimento à dependência química; garantir medicamentos e ações voltadas para prevenção e tratamento em álcool e drogas.

Entre esse total de 19 municípios, apenas 10 registraram no relatório de gestão as dificuldades na implementação das mesmas. Apontaram para metas ainda não alcançadas e apresentaram os altos gastos com internações psiquiátricas de seus munícipes, colocando como desafio o funcionamento do serviço para reduzir as internações. As dificuldades apontadas no relatório relacionam-se a aspectos que envolvem as ações de: atuação de uma equipe interdisciplinar com garantia de atendimento individual e grupal; visitas domiciliares; atendimento à família; acompanhamento terapêutico medicamentoso e oficinas terapêuticas nos municípios com CAPS (2 municípios entre os 10). Isso indica que a atenção oferecida ao usuário da saúde mental nos municípios ainda é incipiente, necessitando de maiores investimentos na área. 
Dos 59 municípios, 40 possuem serviço de saúde mental e 3 possuem em seu planejamento ações a serem desenvolvidas em médio prazo ( 2 anos), cuja meta é a implementação do serviço. Entre os 40 que possuem serviço, 21 não descrevem planejamento de ações em saúde mental e tampouco preveem recursos.

Dentre os 21 municípios que não prestaram contas e não avaliaram suas ações, 8 descreveram o número de internações psiquiátricas por transtornos mentais e comportamentais em função do uso abusivo de bebidas alcoólicas, bem como por doenças relacionadas a esse uso, aumentando ainda mais os gastos com internações.

Os demais não fazem referência à saúde mental e não destacam dados que sugiram investimentos na área.

Do total de municípios com serviços em Saúde Mental, 47,5\% planejaram ações, mas apenas $15 \%$ garantiram recursos, o que representa um entrave para a implementação dessa política. Desse modo, ao mesmo tempo em que a saúde mental apareceu no planejamento, sua configuração não assegura que as ações propostas sejam efetivadas.

Há municípios que afirmam ter os serviços, mas não planejam ações para implementação da política de saúde mental, como também não avaliam no relatório de gestão o processo de organização do trabalho e não propõem readequação das ações para garantir o processo de acompanhamento e avaliação dos dispositivos existentes em seu território. Observou-se que esses municípios, no caso, priorizaram as ações para alcance de indicadores de saúde pactuados com o Ministério da Saúde. Dito de outra forma, foram priorizadas a implantação e a implementação de programas vinculados a repasse de recursos (tuberculose, hanseníase, hipertensão/ diabetes, saúde bucal, entre outros).

\section{Considerações finais}

A implementação da política de saúde mental nos municípios não ocorreu de forma homogênea. Os municípios são dotados de autonomia para decidirem se aderem ou não a determinados programas proposto pelo Ministério da Saúde, e essa adesão é feita com base em um cálculo no qual se avalia os custos e benefícios econômicos e políticos. A prioridade de ação está condicionada aos recursos e à estrutura de que cada administração local dispõe. A capacidade financeira e administrativa da gestão local, além de interferir na própria decisão de assumir a política, pode determinar ainda a extensão e a qualidade dos serviços a serem prestados, como é o caso de alguns municípios que apontam no relatório de gestão dificuldades em garantir a atuação da equipe mínima de saúde mental e espaços adequados para o funcionamento do programa. Outros se limitam a planejar e desenvolver ações de programas que recebem incentivos do Governo Federal.

No caso da saúde mental, por se referir a um programa de transferência de competências, proposto do nível federal para o municipal, presume-se que cada administração local avalie sua respectiva disponibilidade de recursos para arcar com a responsabilidade pública para a gestão do serviço. Variáveis como riqueza econômica, capacidade físcal e capacidade administrativa são componentes do cálculo ou da decisão local que implicará na descentralização das atribuições.

No estado do Espírito Santo, encontrou-se uma variação entre os municípios no que diz respeito à presença das condições necessárias à gestão da política de saúde mental. Existe no estado uma proporção de municípios com reduzida capacidade econômica e dependentes de transferência fiscal, dificultando aos mesmos assumirem responsabilidades na gestão das políticas. Os obstáculos à descentralização da política de saúde mental, nesses casos, podem ser compensados pela ação de governos interessados na transferência das atribuições, possibilitando a adoção de incentivos para que o governo local assuma a gestão.

Os municípios que dispõem de CAPS, com garantia de repasse de recursos do Ministério da Saúde, garantem, em seu plano, recursos de contrapartida municipal para investimentos na área e avaliam suas ações. Os demais que contam com a atuação de uma equipe mínima, sem garantia de recursos do Ministério da Saúde, não asseguram recursos municipais e apontam para a necessidade de implementação de um CAPS - forma legal que garante repasse de recursos para municípios com mais de 20 mil habitantes. Entretanto, os municípios com população inferior não têm perspectiva de garantia de recursos.

Na atenção voltada para a saúde mental, está posto como um dos principais desafios a garantia de recursos voltados para implementar serviços na rede básica ou atenção primária, que deve ser estruturada por um conjunto de ações e serviços. Na organização e estruturação das ações e serviços, o planejamento é um aspecto importante pois possibilita a adoção de estratégias para concretizar as ações. Entretanto, a ausência de recursos previstos pode colocar em risco a execução do planejamento, permitindo afirmar que a configuração das propostas não assegura que as mesmas sejam efetivadas. A não garantia de recursos, voltados para a saúde mental, em $100 \%$ dos municípios, coloca em desvantagem os projetos daqueles com menor capacidade financeira e administrativa e que não se enquadram nos critérios definidos pelo Ministério da Saúde para a captação de recursos voltados para a área. O que leva os municípios a priorizarem programas vinculados a repasses de recursos. 
A priorização dos municípios por estes programas remete ao debate de que a regulamentação da organização e funcionamento do SUS é pautada por financiamento fracionado e fortemente regulado pelo Ministério da Saúde, o que transforma estados e municípios em gestores de projetos e programas federais.

Outro questionamento refere-se à ausência de avaliação dos serviços. Como já apontado, apenas 10 municípios descreveram ações desenvolvidas em saúde mental e relataram dificuldades no processo de implementação destas. A ausência de monitoramento e avaliação pode colocar em risco a eficácia das ações e até mesmo impossibilitar a manutenção e/ou ampliação das mesmas - fato este que leva a questionar em que condições é ofertado o serviço e qual o comprometimento dos gestores e técnicos com a atenção voltada para o doente mental.

Constatou-se que o processo de descentralização da política de saúde mental não possibilitou aos municípios capixabas, de forma homogênea, a existência de um projeto de saúde municipal de base comunitária e territorial. É inaceitável que 37,18\% dos municípios capixabas não assegurassem em 2009 a atenção voltada para a pessoa com transtorno mental, tendo em vista que, pela proposta do Ministério da Saúde, a partir de 2008, as ações de saúde mental na atenção básica podem ser organizadas por meio das equipes da ESF, com apoio de um profissional de saúde mental para realizar ações de matriciamento. Nesse arranjo, o profissional responsável pelo apoio matricial deve participar de reuniões com as ESF para planejar ações, supervisionar e discutir casos e ainda viabilizar capacitações. Assim, 100\% dos municípios capixabas poderiam oferecer na atenção básica uma ação voltada para a pessoa com transtorno mental.

Dessa forma, permanecem desafios cruciais para a política de saúde mental no Espírito Santo (e no Brasil) ainda não equacionados: 1) a inserção da saúde mental na atenção básica; 2) a ampliação e qualificação de leitos em hospitais gerais; 3) melhoria da articulação urgência-emergência/regulação de leitos em alguns municípios de grande porte.

É imprescindível a ampliação dos recursos globais destinados à saúde mental no orçamento geral da saúde (nas três instâncias: federal, estadual e municipal). Há que se garantir o cuidado em saúde mental, a integralidade das ações e a continuidade ao longo do tempo. Isto significa a necessidade de estruturar no Espírito Santo a rede de atenção e evitar a centralização das ações no âmbito da Clínica Santa Isabel. Quanto mais efetiva for a referência extra-hospitalar de atenção, menor será a utilização do dispositivo hospitalar, tanto em número absoluto de internações, quanto em tempo médio de permanência.

\section{Referências}

AMARANTE, P. Saúde mental e atenção psicossocial. Rio de Janeiro: Fiocruz, 2007.

ANDREOLI, S. B. Serviços de saúde mental no Brasil. In: MELLO, M. F. (Org.). Epidemiologia da saúde mental no Brasil. Porto Alegre: Artimed, 2007, p. 85-100.

BRASIL. Instituto Brasileiro de Geografia e Estatística. Contagem da População 2007a. Disponível em: 〈http:// www.ibge.gov.br/home/estatistica/populacao/ contagem2007/default.shtm>. Acesso em: 16 maio 2010.

Ministério da Saúde. Lei n. 10.216, de 06 de abril de 2001. Brasília, 2001. Disponível em: <http:// www.saude.gov.br>. Acesso em: 6 fev. 2010.

Constituição Federal de 1988. Gestão municipal de saúde: leis, normas e portarias atuais. Rio de Janeiro, 2001.

$\overline{\text { Brasília, }} \overline{2001 .}$

Portaria n. 44, de 10 de janeiro de 2001.

Portaria n. 336, de 19 de fevereiro de 2002. Brasília, 2002

Política Nacional de Atenção Básica. 2006. Brasília, 2006

Relatório de gestão 2003-2006. Brasília, 2007. Disponível em: <http://bvsms.saude.gov.br/bvs/ publicacoes/relatorio gestao saude mental 20032006.pdf>. Acesso em: 10 jan. 2010.

Saúde Mental no SUS: Centros de Atenção Psicossocial. Brasília, 2008.

Saúde Mental em Dados 7. Brasília, 2009. Disponível em: <http://portal.saude.gov.br/portal/ arquivos/pdf/smdados.pdf $>$. Acesso em: 16 maio 2010.

Secretaria Estadual de Saúde. Política Estadual de Saúde Mental. Vitória, 2001.

COSTA-ROSA, A.; LUZIO, C. A.; YASUI, S. As conferências nacionais de saúde mental e as premissas do modo psicossocial. Saúde em Debate, v. 25, n. 58, p. 12-25, 2001.

DATASUS. Procedimentos hospitalares por local de internação. 2009. Disponível em: <http://tabnet. datasus.gov.br/cgi/deftohtm.exe?sih/cnv/qies.def>. Acesso em: 15 out. 2009.

ESPÍRITO SANTO. Secretaria Estadual de Saúde. Política Estadual de Saúde Mental. 2001. Vitória, 2001. 
. Portal do Governo do Estado do Espírito Santo. Municípios 2010. Disponível em: <http://www. portaldosmunicipios.es.gov.br>. Acesso em: 5 abr. 2010.

FBH - Federação Brasileira de Hospitais, 2007. Disponível em: 〈http://www.fbh.com.br/index.php?a=fbh midia.php>. Acesso em: 5 abr. 2010.

FERREIRA, L. E. A. Análise de Política Pública de Saúde Mental: o caso do Estado do Espírito Santo. 2005. Dissertação (Mestrado em Saúde Mental) - Programa de Pós-Graduação em Psiquiatria e Saúde Mental, UFRJ, Rio de Janeiro, 2005.

JORGE, M. A. S. et al. Políticas e práticas de saúde mental no Brasil. In: ESCOLA POLITÉCNICA DE SAÚDE JOAQUIM NABUCO.Textos de apoio em políticas de saúde. Rio de Janeiro: Fiocruz, 2005, p. 207- 223.

MAY, T. Pesquisa documental: escavações e evidencias. In: MAY, T. Pesquisa social: questões, métodos e processos. Tradução de Carlos Alberto Silveira Netto Soares. Porto Alegre: Artimed, 2004, p. 200-229.

SOUZA, R. G. Poder local e implementação da política de saúde: dilemas da gestão descentralizada. 2005. 200 p. Tese (Doutorado me Saúde Pública) - Escola Nacional de Saúde Pública Sergio Arouca, Fundação Oswaldo Cruz, Rio de Janeiro, 2005.

TENÓRIO, F. A reforma psiquiátrica brasileira da década de 1980 aos dias atuais: histórias e conceitos. História, Ciência, Saúde-Manguinhos, Rio de Janeiro, v. 9, n. 1, p. 25-59, jan./abr., 2002.

VUORI, H. The Role of the Schools of Public Health in the Development of Primary Health Care. Health Policy, v. 4, n. 3, p. 221-230, 1985.

\section{Notas}

1 Este estudo faz parte do projeto de pesquisa Política de Saúde Mental: análise de política pública financiado pelo Conselho Nacional de Desenvolvimento Científico e Tecnológico (CNPq) (061/2005-proc. n. 400728/2006-0)e Análise da Política de Saúde Mental no ES: entre tramas, redes e atos financiado pela Fundação de Apoio à Ciência e Tecnologia do Espírito (Fapes) e Programa de Pesquisa para o Sistema Único de Saúde (PPSUS/MS) (termo de outorga 37501992/2007).

2 Atenção primária à saúde aqui é entendida como APS, no sentido mais profundo da expressão, quando um sistema de saúde é caracterizado por: justiça social e equidade, autoresponsabilidade, solidariedade internacional e aceitação de um conceito amplo de saúde(VUORI, 1985).
3 Os CAPS deverão constituir-se em serviço ambulatorial de atenção diária que funcione segundo a lógica do território. São classificados em três tipos diferentes, de acordo com sua capacidade de atendimento. O CAPS I atende a uma região de referência, chamada "território" de até 50 mil habitantes; o CAPS II atende a um território de 100 mil habitantes, e o CAPS III, que funciona 24 horas por dia e todos os dias da semana, pode dar cobertura para uma população de até 150 mil habitantes. Os CAPS recebem incentivos financeiros do Ministério da Saúde, de acordo com o seu porte.

4 Segundo parâmetro do Ministério da Saúde, os estados têm uma boa cobertura quando o indicador ultrapassa 0,50 .

5 O vocábulo "louco" aqui é utilizado tão somente para realçar e criticar uso cotidiano do termo, referindo-se àqueles indivíduos considerados pela sociedade como "não normais".

6 Em 2008, o Ministério da Saúde aponta a existência de 1.326 CAPS, nas seguintes modalidades: 618 CAPS I; 382 CAPS II; 39CAPS III; 101 CAPSi e 186CAPSad (BRASIL, 2008). Há estados brasileiros sem CAPS III em seu território (como é o caso do Espírito Santo).

7 Dos 78 municípios capixabas, 43 são considerados de pequeno porte, com menos de 20 mil habitantes.

\section{Edinéia Figueira dos Anjos Oliveira}

eoliveiranjos@yahoo.com.br

Secretária Municipal de Saúde do município de Alfredo Chaves, Espírito Santo

Mestre em Política Social pela Universidade Federal do Espírito Santo (UFES)

\section{Maria Lúcia Teixeira Garcia}

lucia-garcia@uol.com.br

Pós-doutora pela Universidade de Brasília (UnB)

Doutora em Psicologia Social pela Universidade de São Paulo (USP)

Professora do Departamento de Serviço Social da UFES

\section{UFES - Departamento de Serviço Social}

Rua Antônio Honório, 41/502

Bento Ferreira

Vitória - Espírito Santo

CEP: 29050-770 